\title{
Design features of vortex dust collectors
}

\author{
Svetlana Puring ${ }^{1}$, Denis Vatusov ${ }^{1, *}$, and Nicolay Turin ${ }^{1}$ \\ ${ }^{1}$ Samara State Technical University, Institute of Architecture and Civil Engineering, \\ 194, Molodogvardeyskaya St., 443001, Samara, Russia
}

\begin{abstract}
This article states that during the construction of industrial buildings it is necessary to provide engineering communications (including systems of supply and exhaust ventilation) which ensure uninterrupted production, its technological and environmental safety. It is necessary to use cleaning devices to remove pollutants from ventilation emissions in local exhaust systems. As for devices for removing highly disperse nonsticky dust, it is possible to offer vortex dust collectors, the efficiency of which depends on the design and operating mode. A method is proposed to increase the efficiency of a vortex dust collector, to improve the quality of the purified air, and to reduce energy consumption during air purification by installing watering nozzles in primary and secondary air pipes made in the form of a Venturi tube. In consequence of multidirectional movement of dust particles and sprayed water, active coagulation of dust particles takes place, as a result of which the separation increases. Apart from that, watering dusty air flows leads to the formation of a liquid film on the inner surface of the separation chamber, which prevents dust particles from rebounding off the separation chamber and facilitates their capture and flushing into the collecting hopper
\end{abstract}

\section{Introduction}

Effective functioning of industrial buildings is ensured by the installation of necessary engineering services. The systems of supply and exhaust ventilation are one of the basic systems in the construction of buildings. Among many components that ensure the productivity of local exhaust ventilation systems, it is necessary to distinguish air purification devices $[1,2]$.

At present, one of the most effective devices for removing dry fine dust from air is vortex dust collector (VDC). VDCs were for the first time patented in Germany in the 50s of the previous century [3]. As in cyclones, the operating principle of VDCs is based on the action of centrifugal forces. However, in a cyclone the polluted air is supplied through a single inlet, whereas air supply in a VDC is provided through two channels, the lower one and the upper one. The polluted air coming through the lower channel whirls and moves along the axis of the separator chamber upwards, where, under the action of centrifugal forces, dust particles are thrown to the periphery. At the same time, through the upper channel, air (contaminated or clean, depending on the design of the device) is fed, which,

* Corresponding author: vatuzov74@email.ru 
whirls and moves down along the walls of the separator chamber, strengthening the effect of centrifugal forces affecting the dust particles that having reached the wall of the chamber fall down into the receiving hopper. Moreover, unlike cyclones, the use of a VDC makes it possible to achieve effective purification even for highly dispersed particles $\left(d_{p}<1 \mathrm{mkm}\right)$ [4-8].

The main parameters influencing the efficiency of dust collectors, including VDCs, are efficiency of dust collection, hydraulic resistance of the device, its dimensions and cost of cleaning.

Some of these parameters are determined by the internal design features of the device. These include hydraulic resistance, dimensions of the device and efficiency of dust collection.

In addition to internal factors, the cost is also influenced by external ones, coming from the cost of materials and electricity, features of the technological process, etc., the forecasting of which is either difficult or specified by a particular production.

Therefore, the main task of designing an effective VDC is to optimize internal factors $[9,10]$.

\section{Materials and methods}

\subsection{Main theoretical dependencies used in the design of the VDC}

The dimensions of the device are quite a significant factor that determines not only the volume required for the device installation, but also the convenience of installation, operation and maintenance. The required diameter of the device $\mathrm{D}_{1}$ is determined by formula [11]

$$
D_{1}=\sqrt{4 V /\left(\pi u_{g}\right)}
$$

where: $V$ - volumetric flow of dusty gas, $\mathrm{m}^{3} / \mathrm{s} ; u_{g}$ - gas velocity in the working area of the dust collector, $\mathrm{m} / \mathrm{s}$ (recommended to take within $5 \ldots 12 \mathrm{~m} / \mathrm{s}$ ).

The efficiency of cleaning is the main criteria by which the work of the vortex dust collector is evaluated. The degree of air purification (efficiency) is characterized by the ratio of the mass of dust trapped in the device to the mass of dust introduced into it. Since dusty air can be supplied into the dust collector by two streams - through the upper and lower supply pipes, the overall cleaning efficiency will be determined depending on the distribution of the flows along the inputs:

$$
\eta=\left(V_{1} \eta_{1}+V_{2} \eta_{2}\right) V
$$

where: $\eta_{1}, \eta_{2}$ - efficiency of dust collection in primary and secondary gas flows; $V_{1}, V_{2}-$ efficiency of dust collection in primary and secondary gas flows, $\mathrm{m}^{3} / \mathrm{s}$.

In addition to the degree of purification, the minimum particle size fully captured by the vortex dust collector is also of great significance for the device efficiency [4]:

$$
d_{p \min }=\sqrt{\left(18 \mu_{g} u_{g} \ln \left[D_{1} / D_{t}\right]\right) /\left(H\left[\rho_{p}-\rho_{g}\right] \omega^{2}\right)}
$$

where: $H$ - height of dust collecting chamber, $\mathrm{m} ; D_{t}$ - diameter of the branch pipe for the supply of dusty gas, $\mathrm{m} ; \omega$ - angular velocity of the gas flow in the device, $\mathrm{s}^{-1} ; D_{1}$ - device diameter, $\mathrm{m} ; \mu_{g}-$ dynamic viscosity of gas, $\mathrm{Pa} \cdot \mathrm{s} ; \rho_{p}-$ particle density, $\mathrm{kg} / \mathrm{m}^{3} ; \rho_{g}-$ gas density, $\mathrm{kg} / \mathrm{m}^{3}$. 
Hydraulic resistance of the device, $\Delta p, \mathrm{~Pa}$, determines the energy efficiency of the device. The hydraulic resistance of vortex dust collectors is calculated using a ratio similar to that used to calculate cyclones:

$$
P=\xi u_{g}^{2} \rho_{g} / 2
$$

where: $u_{g}$ - gas velocity in the device working zone, $\mathrm{m} / \mathrm{s} ; \xi$ - coefficient of hydraulic resistance, calculated by speed.

Optimization of any of the considered factors leads to an increase in the VDC efficiency.

\subsection{Improving VDC design}

Research on the trajectories of particles, their velocity fields and distribution of static pressures in different areas of the dust collector, revealed the presence of turbulent vortex formations that enable the entrainment of the separated dust into the near-axis zone of the purified gas removed from the VDC. This phenomenon has a significant effect on the degree of cleaning of the dust collector, decreasing it from "theoretically possible" to "practically observed".

Therefore in process of designing such devices, one of the main tasks is to reduce entrainment, and to achieve this various design modifications are applied $[5,7,9]$.

However, despite the design improvements, dry cleaning of dust and gas stream in vortex dust collectors, does not always allow to achieve the required degree of purification, especially from dust of submicron sizes, for a number of certain reasons, associated with the entrainment of this fraction [9]. An additional effect of reducing the entrainment of highly dispersed dust particles can be achieved during wet cleaning.

Therefore, in order to increase the efficiency of the dust collection device, to improve the quality of the cleaned air and to reduce energy consumption during air purification in a vortex dust collector containing a cylindrical separation chamber with upper and lower air supply channels, it is proposed to additionally supply each channel with an injector making it possible to wet the supplied airflow in a device having the form of a Venturi tube [12, 13].

Preliminary coagulation of fine dust particles takes place in wet low-velocity Venturi tubes at flow rates of the cleaned air in the Venturi tube neck $V_{\Gamma}$ to $40 \mathrm{~m} / \mathrm{s}$. Besides, the coefficients of the local resistance of the confuser and diffuser of the Venturi tube are assumed to be minimal. The device in the form of a Venturi tube is characterized by the following parameters: $V_{n} \leq 2 V_{t} ; l_{d i f} \approx 2 l_{c o n} ; d_{n} \approx 0,7 d_{t}\left(V_{t}\right.$ and $V_{n}$ - air velocity in the branch pipe and in the neck, $\mathrm{m} / \mathrm{s} ; l_{\text {dif }}$ - diffuser length, $\mathrm{m} ; l_{\text {con }}-$ confuser length, $\mathrm{m} ; d_{n}, d_{t}-$ diameter of the neck and diameter of the branch pipe, $\mathrm{m}$ ).

\section{Results}

The vortex dust collector (Fig. 1) contains a separation chamber, the upper part of which has an axial branch pipe for discharging purified gas and a branch pipe for introducing secondary air, equipped with a Venturi-type device fitted with a nozzle wetting the secondary airflow, which are installed in front of the Venturi tube and meet the air flow [14].

In the lower part of the housing, there is a branch pipe for the input of the primary dusty air, a blade vortex, a cylinder cowl and a hopper with a lower lateral outlet of the pulp. Similar to the branch pipe for the secondary dusty air, the branch pipe for the input of the 
primary dusty air is equipped with a Venturi-shaped device with a nozzle. Due to the multidirectional movement of dust particles and sprayed water, active coagulation of dust particles and water particles occurs. Rotation of two counter flows (primary and secondary air) inside the separation chamber has one direction.

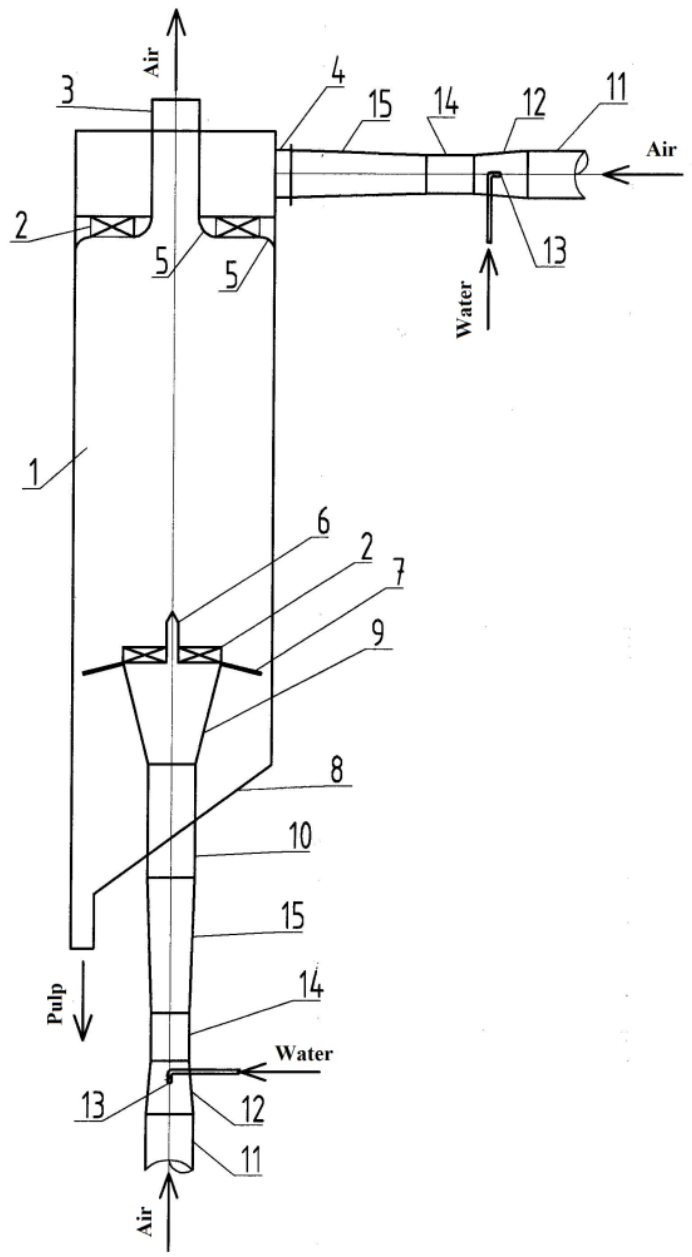

Fig. 1. The longitudinal section of the vortex dust collector: 1 - separation chamber, 2 - blade vortex, 3 - outlet branch pipe, 4 - branch pipe for introducing secondary air, 5 - stabilizing cowl, 6 - cylinder cowl, 7 - bumper washer, 8 - hopper compartment, 9 - stabilizing device, 10 - branch pipe for introducing primary air, 11 - supply air duct, 12 - confusor, 13 - injector, 14 - neck 15 - diffuser.

Enlarged due to coagulation agglomerates are separated efficiently in the separation chamber. Since during the separation the inner surface of the separation chamber gets covered by a film of running water, the fine dust particles moving in the laminar sublayer do not bounce off the inner surface of the separation chamber, but settle on it under the influence of gradient coagulation.

To prevent "overgrowth" of internal surfaces of the vortex dust collector and to improve flushing of the trapped dust, the amount of water sprayed by the injectors into the primary dusty air flow is 2-3 times bigger than into the secondary air flow.

The dispersed composition of the particles sprayed with water jets into the primary air flow is $10 \div 70 \mu \mathrm{m}$, which enables their better separation in the lower part of the separation 
chamber and better flushing of the trapped dust. The dispersed composition of particles sprayed with water jets into the secondary air flow is $2 \div 10 \mu \mathrm{m}$, which provides better mutual coagulation of dust and liquid particles throughout the whole separation chamber.

\section{Discussion}

Thus, the work resulted in creating a VDC of improved design that provides a higher cleaning efficiency.

The use of the device in the form of a low-velocity Venturi tube in the primary and secondary air supply canals reduces energy costs in the process of cleaning dusty air.

This VDC is recommended for removing non-splashing and water-soluble dusts from air during air purification.

\section{Conclusions}

The proposed invention allows to significantly improve the efficiency of the dust collection device and the degree of purification of dusty gases by pre-enlargement of dust particles, the separation of which considerably increases. Furthermore, watering dusty air flows leads to the formation of a liquid film on the inner surface of the separation chamber, which prevents the dust particles from rebounding off the separation chamber and facilitates their capture and flushing into the collecting hopper.

The considered design modifications enable an increase in the degree of purification of the VDC. However, the proposed options do not cover the whole range of possible improvements in vortex dust-cleaning devices and they are only a small link in the chain of possible design innovations.

\section{References}

1. M. B. Generalov [and oth.], Machinery and equipment of chemical and petrochemical industries, Mechanical engineering, P. IV-12 (Mechanical engineering, Moscow, 2004)

2. N.E.Pospelova, E.C.Timirbulatova, Urban Construction and Architecture 3 (16), 84-88 (2014) doi: 10.17673/Vestnik.2014.03.15

3. V.N. Azarov, Dust collectors with counter swirling flow (RPK «Politechnik», Volgograd, 2003)

4. M.V. Vasilievsky, Dedusting of gases by inertial devices (Tomsk Technical University Publishing, Tomsk, 2008)

5. I.A. Khurin, N.P. Turin, Regional architecture and construction 2, 149-154 (2011)

6. V.V. Kuzmin, M.A. Komarov, Modern trends in the development of science and technology V. 8, I. 1, 118-120 (2015)

7. D.V. Azarov, D.P. Borovkov, Biosphere compatibility: people, region, technology 3, 55-60 (2013)

8. U. V. Knyshenko, A. E. Deshko, Technical mechanics, 1, 64-72 (2008)

9. S.M. Puring, D.N. Vatuzov, Modern science: actual problems of theory and practice. Series: Natural and technical sciences 1-2, 10-12 (2013)

10. S.M. Puring, D.N. Vatuzov, N.P. Tyurin, Procedia Engineering 153, 563-568 (2016)

11. V.N. Uzhov, A.U. Waldberg, B.I. Myagkov, I.K. Reshidov, Purification of industrial gases from a dust (Chemistry, Moscow, 1981)

12. M. Balzannikov, S.Piyavsky, A. Kurmanayev, MATEC Web of Conferences 86, 02006 (2016) 
13. E.A.Krestin, Urban Construction and Architecture 2 (23), 48-55 (2016) doi: 10.17673/Vestnik.2016.02.10

14. N.P. Tyurin, D.N. Vatuzov, S.M. Puring, D.N. Tyurin, Vortex dust collector, utility model patent RUS 167446, (2016) 